\title{
EVALUATION OF THE USE OF NARROW IMPLANT FOR REPLACEMENT OF LOWER SINGLE ROOTED TOOTH IN NARROW RIDGE
}

\author{
Ahmed R. Nomer ${ }^{*} B D S$, Saeeda M. Osman² BDS, MSc, PhD, Lydia N. Melek ${ }^{3} B D S, M S c, P h D$
}

\begin{abstract}
INTRODUCTION: The possibility of placing implants can sometimes be limited due to physical conditions e.g. where the horizontal space is limited by adjacent teeth and roots, or in situations with a narrow alveolar ridge. By using a narrow implant, the need for bone augmentation or orthodontic tooth movement can be avoided.

OBJECTIVES: This study was designed to evaluate the use of narrow implants for replacement of lower single rooted teeth in narrow lower ridge.

MATERIALS AND METHODS: Ten patients were selected from the Department of Oral and Maxillofacial Surgery, Faculty of Dentistry, Alexandria University with missing lower single rooted tooth or teeth and narrow ridge ( $6 \mathrm{~mm}$ thick or less) then implants were placed and they were evaluated by radiographic examination to evaluate the bone density around the implants after 1, 3,6 months.

RESULTS: The mean periimplant probing depth was $2.18 \pm 0.55$ on the 3rd month and $1.50 \pm 0.52$ on the 6th month, there was statistically significant decrease. As for the mean marginal bone height was $0 \pm 0$ immediately postoperative, $0.26 \pm 0.14$ on the 3 rd month and $0.45 \pm 0.16$ on the 6th month, there was statistically significant increase. Also the results of the present study showed the mean bone density was $79.63 \pm$ 8.55 immediately postoperative then increased on the 3rd month to be $86.35 \pm 6.48$ and $92.01 \pm 5.49$ on the 6 th month, there was statistically significant increase.
\end{abstract}

CONCLUSIONS: Narrow diameter implants can be used to restore missing single rooted teeth with narrow ridge.

KEY WORDS: Narrow implant, narrow ridge, bone density.

1- Bachelor of Dentistry, BDS, Faculty of Dentistry, Alexandria University, Alexandria, Egypt.

2- Professor of Oral and Maxillofacial Surgery, BDS, MSc, PhD, Faculty of Dentistry, Alexandria University, Alexandria, Egypt.

3- Lecturer of Oral and Maxillofacial Surgery, BDS, MSc, PhD, Faculty of Dentistry, Alexandria University, Alexandria, Egypt.

\section{INTRODUCTION}

According to the World Health Organization, edentulism has an important adverse impact on the individual, in some cultures and, on the community as well (1). Dental implants are a valid treatment modality for the completely $(2,3)$ or partially $(4,5)$ edentulous patient. A single-tooth implant can be a good solution, although not an easy one. Implant treatment for a single missing tooth can potentially lead to a well-functioning and an esthetically pleasing single crown on an implant $(6,7)$.

The possibility of placing implants can sometimes be limited due to physical conditions e.g. where the horizontal space is limited by adjacent teeth and roots, or in situations with a narrow alveolar ridge. By using a narrow implant, the need for bone augmentation or orthodontic tooth movement can be avoided. In situations with limited horizontal space a narrow diameter implant may be the only option to replace a missing tooth, several studies evaluating the clinical outcome of narrow implants $(<3.5 \mathrm{~mm}$ in diameter $)$ in general, placed in different indications are available. Narrow implants supporting single tooth replacements have shown favorable clinical results (8) in the long-term perspective $(9,10)$. Moreover, studies evaluating fixed partial dentures have shown good clinical results both after short and long-term follow-up periods $(9,11,12)$.

Narrow implants have also been used to support full arch reconstructions, and satisfactory results have been shown for fixed bridges and overdentures in the mandible and in the maxilla $(9,13-15)$. In general, no difference in the clinical outcome between standard diameter implants and narrow implants has been observed $(8,16-18)$.
The choice of implant diameter depends on the type of edentulism, the volume of the residual bone, the amount of space available for the prosthetic reconstruction, the emergence profile, and the type of occlusion. Narrow diameter implants (NDIs; diameter $<3.5 \mathrm{~mm}$ ) have specific clinical indications, e.g., where there is reduced inter radicular bone or a thin alveolar crest, and for the replacement of teeth with a small cervical diameter (8).

NDIs supporting single tooth replacements have shown favorable clinical results in the long-term perspective (8). Small diameter implants have been indicated in the incisor region for the maxilla and mandible primarily; their usage should be considered in select posterior regions. The use of NDI in these regions was always controversial due to the expectation that posterior teeth region is considered as loadbearing regions and due to high load the dental implant would fail. NDIs have been available in clinical practice since the 1990s, but only a few studies have analyzed their clinical outcome $(19,20)$.

The definition of a narrow-diameter implant is subject to controversy. Although no universally accepted classification of implant diameters has been established to date, a narrow-diameter implant is generally taken to have a diameter from $3.0 \mathrm{~mm}$ and $3.5 \mathrm{~mm}$. Some recent studies with narrow-diameter implants have reported implant success and survival rates similar to those obtained with greater diameter implants $(20,21)$.

Therefore, this study was conducted to evaluate the use of narrow dental implants in for the replacement of mandibular single rooted teeth in narrow mandibular ridges. 


\section{MATERIALS AND METHODS}

A clinical trial was conducted on ten patients of both sexes suffering from missing mandibular single rooted teeth with narrow ridge. Patients were selected from the outpatient clinic of the Oral and Maxillofacial Surgery Department, Faculty of Dentistry, Alexandria University. An appropriate ethical clearance has been obtained from the faculty and the informed consent have been signed by patients.

The inclusion criteria of this study were: patients age ranging from 25-50 years, missing mandibular single rooted tooth or teeth with narrow ridge ( $6 \mathrm{~mm}$ or less), adequate interocclusal space for implant placement and good oral hygiene. While the exclusion criteria were: inadequate occlusal space, parafunctional habits as bruxism, uncontrolled systemic disease as uncontrolled diabetes, patients receiving chemotherapy or radiotherapy.

\section{Implant system}

Dentium system narrow diameter implant with a diameter $3.00 \mathrm{~mm}$ and varying lengths $(9,11,13 \mathrm{~mm})$.

The narrow diameter implant is narrow but strong, it has $3.0 \mathrm{~mm}$ body fixture diameter which is very useful for narrow ridge, the conical square connection between the implant and the abutment ensures hermetic sealing and also the aggressive thread design, tapered design may be effective to get primary stability.

\section{Implant placement procedures}

All patients underwent pre-operative clinical examination; patient's data were collected; name, gender, age and dental history were taken and the oral mucosa of the edentulous area was examined for color, firmness and thickness. Also all patients underwent pre-operative radiographic examination using CBCT to measure the available bone, Selection of the right size implant for optimal support, Precision placement of implants in the bone, their relation to adjacent structures and to evaluate the condition of bone. (Fig 1)
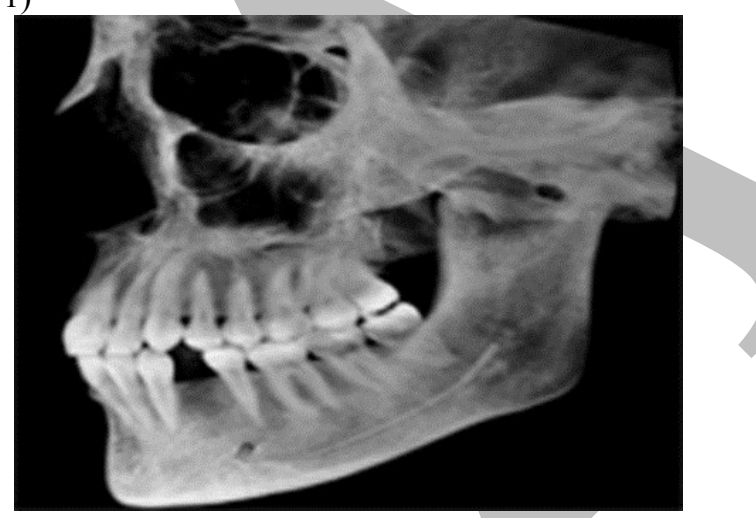

Figure 1: Photograph showing cone beam C.T showing missing mandibular left first premolar.

Preoperative oral antibiotics one hour before surgery was given Amoxicillin/clavulanic acid 2 gm (Augmentim: GSK GlaxoSmitheKline, Boomerang building no 46, Block (j) first section city center -New cairo, Cairo, Egypt) and $0.12 \%$ chlorhexidine gluconate (Hexitol: the Arab drug CO. Cairo, A.R) mouth wash was used to rinse for 30 seconds before operation.

With the patient under local anesthesia (infiltration anesthesia) (Articaine HCL with epinephrine 1:100,000) (Ubistesin forte, 3M Deutschiand GmbH Carl-strabe 7 41453 Neuss, Germany) a full thickness mucoperiosteal envelope flap was raised, osteotomy was carried out in the central part of the alveolar bone, the initial marking or preparation of the implant site was done with a pilot drill of $2.2 \mathrm{~mm}$, the osteotomy was then widened using an intermediate drill and the final drill according to the diameter of the implant, the implant was then threaded into the bone using Ratchet, then the cover screw was placed, and the flap was sutured around the fixtures using $3 / 0$ black silk suture. (Fig 2)

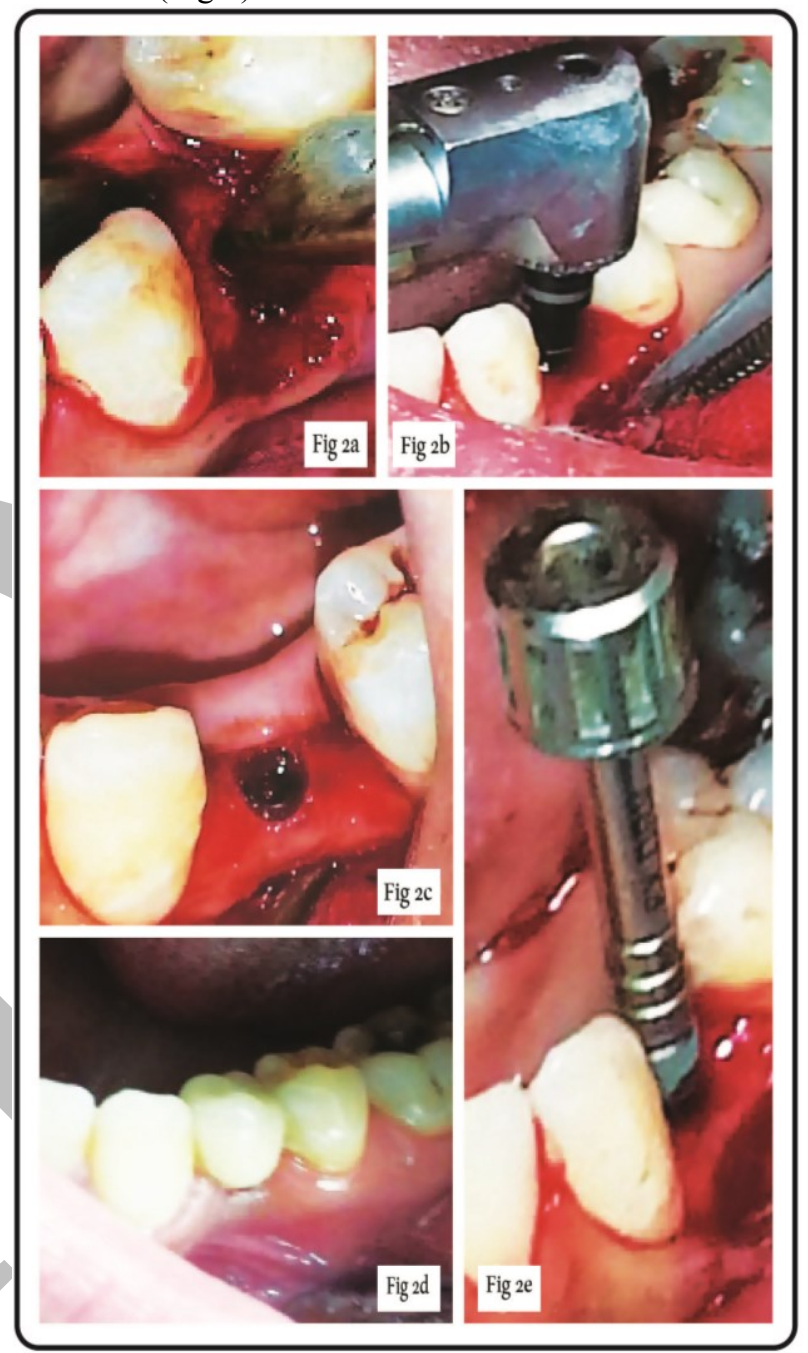

Figure 2: a. Photograph showing the mucoperiosteal envelope flap reflection.
b. Photograph showing first drilling.
c. Photograph showing cover screw.
d. photograph showing final prosthesis.
e. Photograph showing the implant insertion.

All patients were advised to apply cold packs extra orally intermittently every 10 minutes for 2 hours on the first day, chlorohexidine mouth (Hexitol: The Arab drug CO. Cairo, a.R) wash was started on the 2 nd post-operative day 3 times daily for 2 weeks, the sutures were removed after one week post surgically. Antibiotic Amoxicillin/clavulanic acid 1gm tab (Augmentim: GSK GlaxoSmitheKline, Boomerang building no 46, Block (j) first section city center -New cairo, Cairo, Egypt) 2 times daily for 5 days, non-steroidal antiinflammatory drugs ibuprofen $400 \mathrm{mg}$ (Ibuprofen: EIPICO, 10th of Ramadan city, industrial zone B1, Egypt), 3 times daily for 3 days were given. 


\section{Follow up phase}

All patients were evaluated immediately post-operatively and on intervals of $3 \& 6$ months, for presence of pain, swelling or infection using Visual Analogue Scale (22) (VAS), gingival inflammation using the Löe and Silness Gingival Index (23) on the 2 nd and 7 th post-operative days and implant mobility was tested according to Mickney and Koth (24).

All the implants involved in this study were radiographed by panoramic immediately post operatively and on intervals of $3 \& 6$ months to assess the marginal bone height and bone density around the implants using J-image program (25). (Fig 3)

Final prosthesis (porcelain fused to metal crown) was placed after three months.

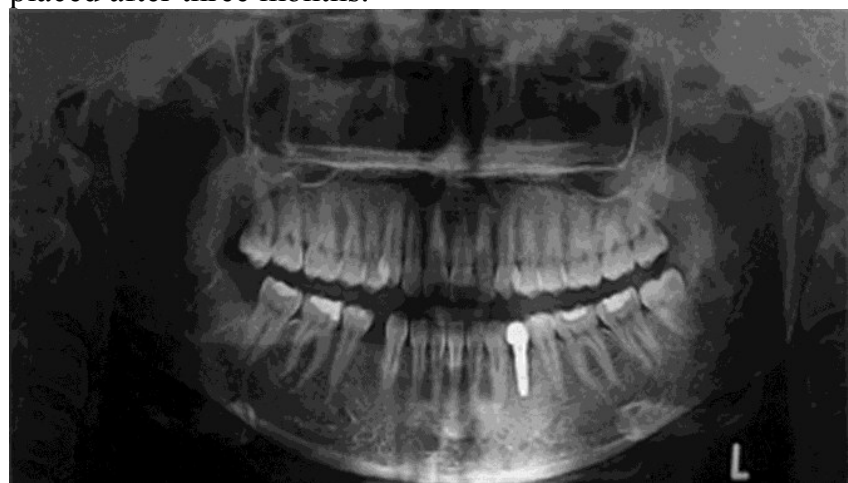

Figure 3: Postoperative panoramic radiograph after three month

The statistical analysis was performed to evaluate the bone density immediately post-operative and on intervals of 3 and 6. Data were fed to the computer and analyzed using IBM SPSS software package version 20.0.

The used tests were:

1- $\quad$ Paired t-test

For normally quantitative variables, to compare between two periods.

2- $\quad$ ANOVA with repeated measures

For normally quantitative variables, to compare between more than two periods or stages, and Post Hoc test (LSD) for pairwise comparisons.

3- Wilcoxon signed ranks test

For abnormally quantitative variables, to compare between two periods.

4- $\quad$ Chi square for Friedman test

For abnormally quantitative variables, to compare between more than two periods or stages.

\section{RESULTS}

A total of ten patients ( 7 females and 3 males) having missing mandibular single rooted teeth with narrow ridge were included in this study. Their ages ranged between 25 and 50 years with mean age of 30 years. Three patients with missing left mandibular first premolar $(6 \mathrm{~mm}, 5.5 \mathrm{~mm}$ width of bone), two patients with missing right mandibular first premolar $(5 \mathrm{~mm})$ and five patients with missing mandibular centrals, laterals, canine (all with $5.8 \mathrm{~mm}$ thickness). They were selected from the Outpatient Clinic of the Oral and Maxillofacial Surgery Department, Faculty of Dentistry, Alexandria University. All patients had undergone surgical procedures for delayed implant placement and loading. All patients were followed up both clinically and radiographically for 6 months.
All patients had been operated under local anesthesia using surgical flap technique and implant placement, and no complications had been recorded during the operation.

All patients had been examined periodically during the follow-up period up to 6 months. Healing was uneventful in all cases with no post-operative complications. Other clinical parameters had been recorded such as: Pain index, gingival index, implant mobility.

1) Pain, Tenderness, Infection and/or Swelling

After surgery, all patients experienced slight to mild pain at the surgical site. One had slight pain and showed mild oedema which subsided totally by the $2^{\text {nd }}$ post-operative day. Six patients had mild pain and mild oedema which also disappeared completely by the $3^{\text {nd }}$ post-operative day. Three patients experienced mild pain and moderate edema, which subsided totally by the $2^{\text {th }}$ post-operative day.

All patients continued the follow up period without any signs of infection, gingivitis. (Fig 4a)

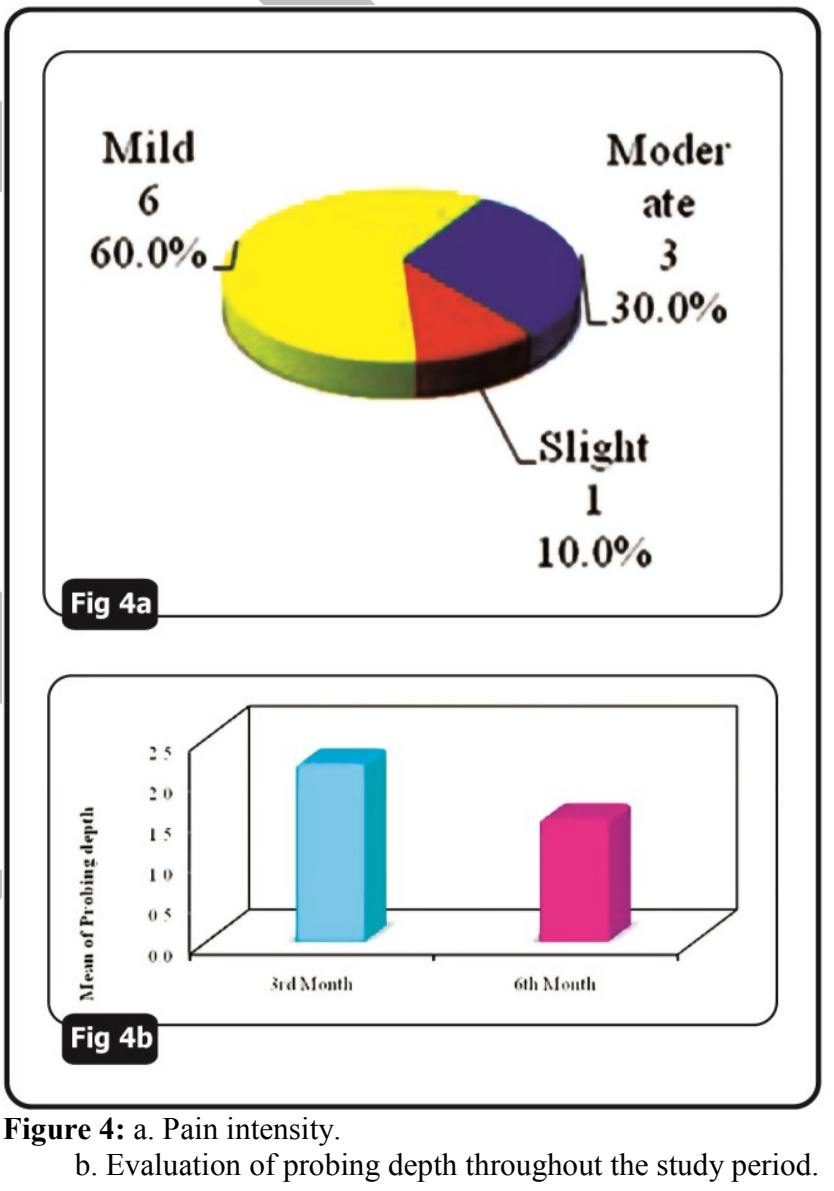

2) Gingival Index

All over the evaluation period no signs of gingival inflammation were observed in all patients. (I.e. gingival index score was 0 )

3) Implant mobility

All over the evaluation period, none of the implants showed any signs of mobility. (i.e. mobility score was 0 )

4) Peri-implant probing depth by Glavind and Loe(26)

On the third month, the mean probing depth scores was 2.18 \pm 0.55 with a minimum recorded value of 1.5 and a maximum recorded value of 3.00 .

On the sixth month, the mean probing depth scores was $1.50 \pm 0.52$ with a minimum recorded value of 0.75 and a 
maximum recorded value of 2.25 , this difference in the probing depth score between the study periods was found to be statistically significant. $\left(\mathrm{p}<0.001^{*}\right)$ (Table 1, Fig4b)

Table (1): Comparison between $3^{\text {rd }}$ month and $6^{\text {th }}$ month according to probing depth throughout evaluation peroid.

\begin{tabular}{|l|c|c|c|c|}
\hline \multirow{2}{*}{} & \multicolumn{2}{|c|}{ Probing depth } & \multirow{2}{*}{ T } & P \\
\cline { 2 - 3 } & $\begin{array}{c}\mathbf{3}^{\text {rd }} \\
\text { Month } \\
(\mathbf{n}=\mathbf{1 0})\end{array}$ & $\begin{array}{c}\mathbf{6}^{\text {th }} \text { Month } \\
(\mathbf{n}=\mathbf{1 0})\end{array}$ & & \\
\hline Min. - & $1.50-3.0$ & $0.75-$ & & \\
Max. & 2.25 & & \\
Mean \pm & $2.18 \pm$ & $1.50 \pm$ & & \\
SD. & 0.55 & 0.52 & $9.450^{*}$ & $<0.001^{*}$ \\
Median. & 2.0 & 1.50 & & \\
\hline
\end{tabular}

\section{t: Paired t-test}

$*$ : Statistically significant at $\mathrm{p} \leq 0.05$

\section{Radiographic evaluation Marginal bone height}

Immediately post-operatively, the mean marginal bone level value was $0 \pm 0$ with a minimum recorded value of 0 and a maximum recorded value of 0 , showing no statistically significant difference between the two periods.

On the third month, the mean marginal bone level value was $0.26 \pm 0.14$ with a minimum recorded value of 0.1 and a maximum recorded value of 0.55 .

On the sixth month, the mean marginal bone level value was $0.45 \pm 0.16$ with a minimum recorded value of 0.23 and a maximum recorded value of 0.80 This difference in marginal bone level value between the $3 \mathrm{rd}$ and 6 th was found to be statistically significant. $\left(\mathrm{p}=0.005^{*}\right)$ (Table 2 , Fig 5)

Table (2): Comparison between $3^{\text {rd }}$ month and $6^{\text {th }}$ month according to marginal bone height at the mesial and distal aspects of all implants.

\begin{tabular}{|c|c|c|c|c|}
\hline \multirow{2}{*}{} & \multicolumn{3}{|c|}{ Marginal bone height } & \multirow{2}{*}{ P } \\
\cline { 2 - 5 } & $\begin{array}{c}\text { Immediate } \\
\text { postoperative } \\
(\mathbf{n}=\mathbf{1 0})\end{array}$ & $\begin{array}{c}\mathbf{3}^{\text {rd }} \\
\text { Month } \\
(\mathbf{n}=\mathbf{1 0})\end{array}$ & $\begin{array}{c}\mathbf{6}^{\text {th }} \\
\text { Month }^{\mathbf{n}=\mathbf{1 0})}\end{array}$ & \\
\hline $\begin{array}{c}\text { Min. }- \\
\text { Max. }\end{array}$ & $0.0-0.0$ & $\begin{array}{c}0.10- \\
0.55\end{array}$ & $\begin{array}{c}0.23- \\
0.80\end{array}$ & \\
$\begin{array}{c}\text { Mean } \pm \\
\text { SD. }\end{array}$ & $0.0 \pm 0.0$ & $\begin{array}{c}0.26 \pm \\
0.14\end{array}$ & $\begin{array}{c}0.45 \pm \\
0.16\end{array}$ & $<0.001^{*}$ \\
$\begin{array}{c}\text { Median. } \\
\text { Sig. bet. } \\
\text { periods }\end{array}$ & 0.0 & 0.22 & 0.46 & \\
\hline
\end{tabular}

p: $p$ value for Friedman Test

Sig. bet. periods were done using Wilcoxon Signed Ranks Test

$\mathrm{p}_{1}: \mathrm{p}$ value for comparing between Immediate postoperative and $3^{\text {rd }}$ month $\mathrm{p}_{2}: \mathrm{p}$ value for comparing between Immediate postoperative and $6^{\text {th }}$ month $\mathrm{p}_{3}$ : $\mathrm{p}$ value for comparing between $3^{\text {rd }}$ Month and $6^{\text {th }}$ month

*: Statistically significant at $\mathrm{p} \leq 0.05$

\section{Evaluation of bone density around the implant}

Immediately post-operatively, the mean peri-implant bone density value was $79.63 \pm 8.55$ with a minimum recorded value of 67.18 and a maximum recorded value of 93.63.
On the third month, the mean peri-implant bone density value was $86.35 \pm 6.48$ with a minimum recorded value of 76.50 and a maximum recorded value of 98.10 .

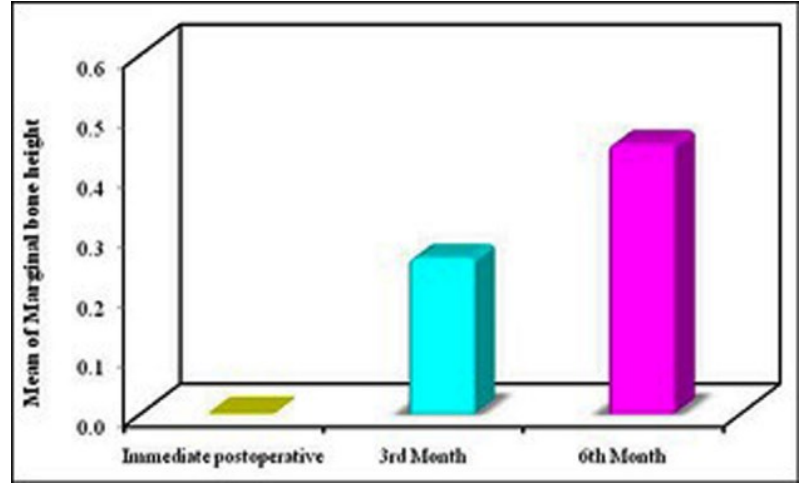

Figure 5: Evaluation of the Marginal bone height throughout the study period.

On the sixth month, the mean peri-implant bone density value was $92.01 \pm 5.49$ with a minimum recorded value of 81.0 and a maximum recorded value of 99.59 , this difference in peri-implant bone density value throughout the study period was statistically significant. $\left(p<0.001^{*}\right)$ (Table 3, Fig 6)

Table (3): Comparison between $3^{\text {rd }}$ month and $6^{\text {th }}$ month according to bone density around the implant.

\begin{tabular}{|c|c|c|c|c|}
\hline & \multicolumn{3}{|c|}{ Bone density around the implant } & \multirow[b]{2}{*}{$\mathbf{P}$} \\
\hline & $\begin{array}{c}\text { Immediate } \\
\text { postoperative } \\
(\mathrm{n}=10)\end{array}$ & $\begin{array}{c}3^{\text {rd }} \\
\text { Month }^{\text {ronth }} \\
\text { (n } \\
=10)\end{array}$ & $\begin{array}{c}\mathbf{6}^{\text {th }} \\
\text { Month } \\
\quad(\mathbf{n} \\
=10)\end{array}$ & \\
\hline $\begin{array}{l}\text { Min. - } \\
\text { Max. }\end{array}$ & $67.18-93.63$ & $\begin{array}{c}76.50 \\
- \\
98.10\end{array}$ & $\begin{array}{l}81.0- \\
99.59\end{array}$ & \\
\hline $\begin{array}{c}\text { Mean } \pm \\
\text { SD. }\end{array}$ & $79.63 \pm 8.55$ & $\begin{array}{l}86.35 \\
\pm 6.48\end{array}$ & $\begin{array}{l}92.01 \\
\pm 5.49\end{array}$ & $<0.001^{*}$ \\
\hline Median. & 79.91 & 87.11 & 93.58 & \\
\hline $\begin{array}{l}\text { Sig. bet. } \\
\text { periods }\end{array}$ & \multicolumn{3}{|c|}{$\mathrm{p}_{1}<0.001^{*}, \mathrm{p}_{2}<0.001^{*}, \mathrm{p}_{3}=0.002^{*}$} & \\
\hline
\end{tabular}

$\mathrm{p}$ : $\mathrm{p}$ value for $\mathrm{F}$ test (ANOVA) with repeated measures,

Sig. bet. periods were done using Post Hoc Test (LSD) for ANOVA with repeated measures

$\mathrm{p}_{1}$ : $\mathrm{p}$ value for comparing between Immediate postoperative and $3^{\text {rd }}$ month

$\mathrm{p}_{2}: \mathrm{p}$ value for comparing between Immediate postoperative and $6^{\text {th }}$ month

p3: $p$ value for comparing between $3^{\text {rd }}$ Month and $6^{\text {th }}$ month *: Statistically significant at $\mathrm{p} \leq 0.05$

\section{DISCUSSION}

The foundation of any structure or building has to be solid and architecturally sound to withstand any exerted force from any direction. The bioengineering of dental implants has always favored wide diameter dental implants. Logic says the wider the surface, the better tolerance of withstanding forces exerted on the crown, which extends to the dental implants. Major dental advancements have led dental implants to remarkably high routine success rates. Advancements in technology have introduced the ability to restore severely compromised sites such as knife edge bone 
structures or those with minimum bone volume buccolingually. Expectations for narrow diameter dental implants have flourished due to their improved success (10).

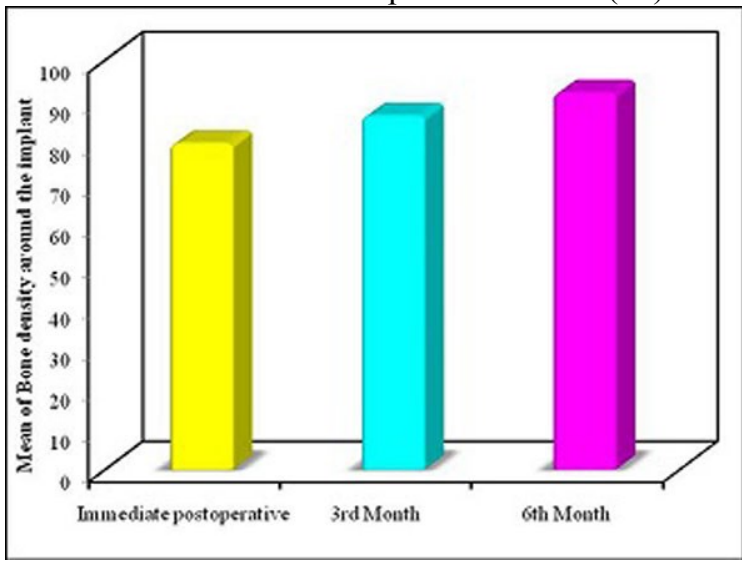

Figure 6: Evaluation of the peri-implant bone density throughout the study period.

The present study was conducted on ten patients (7 females and 3 males) selected from the Outpatient Clinic of the Oral and Maxillofacial Surgery Department, Faculty of Dentistry, Alexandria University. Each had extracted mandibular single rooted teeth with narrow ridge. Their ages ranged between 25 and 50 years with mean age of 30 . The selected patients were free from any uncontrolled systemic diseases or conditions that may complicate the surgical procedure or the healing process of the implant. This was following a study performed by Bornstein et al (27) where they reviewed whether systemic diseases with/without systemic medications increased the risk of implant failure and therefore diminish the success and survival rates of dental implants. They stated that the level of evidence indicative of absolute and relative contraindications for implant therapy due to systemic diseases is low.

In the current study strict oral hygiene was followed by all patients during the preoperative and postoperative follow up. A number of reports of dental implants procedures have highlighted the value of maintaining strict oral hygiene measurements and using antibiotics preoperatively. Implant placement procedures run a risk of introducing new bacteria, requiring the use of prophylactic antibiotics to prevent the infection. The antibiotic administration has been demonstrated not only to minimize the incidence of postoperative infection but also to significantly reduce the rate of implant failure (28).

This was following a study performed by Dent et al (29) where they recorded the data about preoperative or postoperative use of antibiotics, the type used and the duration of coverage and correlated it with failure of osseointegration during healing at stage I and at stage II surgery. Their results showed that significantly fewer failures occurred when preoperative antibiotics were used.

As regards the surgical procedure, all included patients were subjected to delicate surgery using the delayed surgical placement and loading protocols. A low speed high torque hand piece was used for the preparation of the implant bed, and the drilling was performed under profuse irrigation using cold normal saline for proper cooling and to avoid overheating of the bone tissues which would compromise osseointegration in accordance to Strbac et al (30).

In the present study, wound closure was performed very carefully using 3/0 silk suture material in order to prevent postoperative infection and inflammation, epithelial down growth and bone loss of the alveolar crest during the healing period as recommended by Becker and Becker (31).

Regarding the implant mobility, no clinical mobility was detected in any of the implants after insertion. This was confirmed by the radiographic evaluation that revealed intimate bone- implant contact and bone density in all implants. The absence of implant mobility is one of the most important criteria for implant success in accordance with Roos et al (32). This also agrees with Albrekstsson et al (33).

Regarding the gingival condition around the implants, all cases showed a modified gingival score of 0 throughout the evalution period indicating absence of peri-implant mucositis, which is a criteria of implant success as periimplant mucositis may lead to progressive bone destruction (peri-implantitis) and ultimately to implant failure as reported by Esposito et al (34). Khammissa et al (35) also stated that the extension of peri-implant mucositis can spread to the bone leading to peri-implantitis and implant failure.

In this study the peri-implant probing depth showed statistically significant lesser probing depth values on the 3rd and 6th months postoperatively. This implies that a soft tissue seal above the bone has been established in the implanted sites. Soft tissue integrity plays a principal role in the maintenance of the periimplant bone levels. In our study, absence of bleeding on probing at the 6-month visit was associated with the maintenance of marginal bone levels from the crown placement, concerning those implants that showed bleeding on probing at the follow-up visit. Absence of inflammation could justify this difference, because the absence of pro-inflammatory cytokines protects this environment from protein-mediated resorption and this agrees with Loomer et al. (36) and Kinane DF, and Lappin DF (37).

In the present studies, standardized periapical and panoramic radiographs using long-cone paralleling technique with XCP film holding device were performed immediately post-surgery then after 3 and 6 months during the follow-up period to measure peri-implant bone height and to detect changes in bone density surrounding dental implants. Radiograph analysis was done using image $\mathrm{J}$ software (38).

In this study, the mean of marginal bone height increased significally towards the 6th month postoperatively. Similarly, Degidi et al (21) found a better outcome with regard to reduced crestal bone loss over time for narrow implants.

Regarding peri-implant bone density, the current work revealed statistically significant increase in bone density around the implants starting from the immediate postoperative period to the end of the 6 month of the evaluation period. This can attribute to the healing of the bone around implants, this is in agreement with Han and Park. (39) And also agrees with Barunawarty (40), in his study approved that bone density increased around dental implant after placement of dental implants. 


\section{CONCLUSIONS}

Narrow diameter implants can be used to restore missing single rooted tooth or teeth with narrow ridge in the mandible.

\section{STATEMENT OF CONFLICT OF INTEREST}

The authors declare that they have no conflicts of interest.

\section{REFERENCES}

1. World Health Organisation (WHO). Oral Health in the African Region: A Regional Strategy1999-2008. Harare: WHO Regional Office for Africa, 2000.

2. Adell R, Lekholm U, Rockler B, Brånemark PI. A 15-year study of osseointegrated implants in the treatment of the edentulous jaw. Int J Oral Surg. 1981; 10: 387-416.

3. Lindquist LW, Carlsson GE, JemtT. A prospective 15-year follow-up study of mandibular fixed prosthesis supported by osseointegrated implants: clinical results and marginal bone loss. Clin Oral Implants Res. 1996; 7: 329-36.

4. Jemt T, Lekholm U, Adell R. Osseointegrated implants in the treatment of partially edentulous patients: a preliminary study on 876 consecutively placed fixtures. Int J Oral Maxillofac Implants. 1989; 4: 211-7.

5. Jemt T, Patterson P. A 3 year follow up study on single implant treatment. J Dent. 1993; 21: 203-8.

6. Simon RL. Single implant-supported molar and premolar crowns: a ten-year retrospective clinical report. J Prosthet Dent. 2003; 90: 517-21.

7. Gibbard LL, Zarb G. A 5-year prospective study of implantsupported single-tooth replacements. J Can Dent Assoc. 2002; 68: 110-6.

8. Andersen E, Saxegaard E, Knutsen BM, Haanaes HR. A prospective clinical study evaluating the safety and effectiveness of narrow-diameter threaded implants in the anterior region of the maxilla. Int $\mathrm{J}$ Oral Maxillofac Implants. 2001; 16: 217-24.

9. Zinsli B, Sagesser T, Mericske E, Mericske- Stern R. Clinical evaluation of small-diameter ITI implants: a prospective study. Int J Oral Maxillofac Implants. 2004; 19: 92-9.

10. Polizzi G, Fabbro S, Furri M, Herrmann I, Squarzoni S. Clinical application of narrow Branemark System implants for single-tooth restorations. Int J Oral Maxillofac Implants. 1999; 14: 496-503.

11. Comfort MB, Chu FC, Chai J, Wat PY, Chow TW. A 5-year prospective study on small diameter screw-shaped oral implants. J Oral Rehabil. 2005; 32: 341-5.

12. Lee JS, Kim HM, Kim CS, Choi SH, Chai JK, Jung UW. Long-term retrospective study of narrow implants for fixed dental prostheses. Clin Oral Implants Res. 2013; 24: 84752.

13. Cho SC, Froum S, Tai CH, Cho YS, Elian N, Tarnow DP. Immediate loading of narrow-diameter implants with overdentures in severely atrophic mandibles. Pract Proced Aesthet Dent. 2007; 19: 167-74.

14. Spiekermann H, Jansen VK, Richter EJ. A 10- year followup study of IMZ and TPS implants in the edentulous mandible using bar-retained overdentures. Int $\mathrm{J}$ Oral Maxillofac Implants. 1995; 10: 231-43.

15. Payne AG, Tawse-Smith A, Thomson WM, Duncan WD, Kumara R. One-stage surgery and early loading of three implants for maxillary overdentures: a 1-year report. Clin Implant Dent Relat Res. 2004; 6: 61-74.

16. Mericske-Stern R, Grutter L, Rosch R, Mericske E. Clinical evaluation and prosthetic complications of single tooth replacements by non-submerged implants. Clin Oral Implants Res. 2001; 12: 309-18.

17. Weng D, Jacobson Z, Tarnow D, Hürzeler MB, Faehn O, Sanavi F, et al. A prospective multicenter clinical trial of $3 i$ machined-surface implants: results after 6 years of followup. Int J Oral Maxillofac Implants. 2003; 18: 417-23.

18. Renouard F, Nisand D. Impact of implant length and diameter on survival rates. Clin Oral Implants Res. 2006; 17(Suppl): 35-51.

19. Davarpanah M, Martinez H, Tecucianu JF, Celletti R, Lazzara R. Small-diameter implants: Indications and contraindications. J Esthet Dent. 2000; 12: 186-94.

20. Sohrabi K, Mushantat A, Esfandiari S, Feine J. How successful are small-diameter implants? A literature review. Clin Oral Impl Res. 2012; 23: 515-25.

21. Degidi M, Piatelli A, Carinci F. Clinical outcome of narrow diameter implants: a retrospective study of 510 implants. J Periodontol. 2008; 79: 49-54.

22. Boonstra AM, Schiphorst Preuper HR, Reneman MF, Posthumus JB, Stewart RE. Reliability and validity of the visual analogue scale for disability in patients with chronic musculoskeletal pain. Int J Rehabil Res. 2008; 31: 165-9.

23. McClanahan SF, Bartizek RD, Biesbrock AR. Identification and consequences of distinct Löe-Silness gingival index examiner styles for the clinical assessment of gingivitis. $\mathbf{J}$ Periodontol. 2001; 72: 383-92.

24. Steflik D, Koth DL, Robinson F, McKinney R, Davis B, Morris $\mathrm{C}$, et al. Prospective investigation of the singlecrystal sapphire endosteal dental implant in humans: Tenyear results. J Oral Implantol. 1995; 21: 8-18.

25. Abramoff MD, Magelhaes PJ, Ram SJ. Image processing with Image. J Biophotonics International. 2004; 11: 36-42.

26. Becker W, Hujoel $P$, Becker B, Willingham $H$. Osteoporosis and implant failure: An exploratory casecontrol study. J Peiodontol. 2000; 71: 625-31.

27. Bornstein MM, Cionca N, Mombelli A. Systemic conditions and treatments as risks for implant therapy. Int $\mathrm{J}$ Oral Maxillofac Implants. 2009; 24: 12-27.

28. Duyck J,Naert I Failure of oral implants: aetiology, symptoms and influencing factors. Clin Oral Investig. 1998; 2: $102-14$.

29. Dent CD, Olson JW, Farish SE, Bellome J, Casino AJ, Morris HF, et al. The influence of preoperative antibiotics on success of endosseous implants up to and including stage II surgery: a study of 2,641 implants. J Oral Maxillofac Surg. 1997; 55: 19-24.

30. Strbac GD, Unger E, Donner R, Bijak M, Watzek G, Zechner W. Thermal effects of a combined irrigation method during implant site drilling. A standardized in vitro study using a bovine rib model. Clin Oral Implants Res. 2014; 25: 665-74.

31. Becker W, Becker B. Guided tissue regeneration for implants placed into extraction sockets and for implant dehiscence: Surgical techniques and case reports. Int $\mathrm{J}$ Period Res Dent. 1990; 10: 376-91.

32. Roos J, Sennerby L, Lekholm U, Jemt T, Grondahl K, Albrektsson T. A qualitative and quantitative method for evaluating implant success: a 5-year retrospective analysis 
of the Branemark implant. Int J Oral Maxillofac Implants. 1997; 12: 504-14.

33. Albrektsson T, Zarb G, Worthington P, Eriksson AR. The long term efficacy of currently used dental implants: A review and proposed criteria of success. Int $\mathrm{J}$ Oral Maxillofac Implants. 1986; 1: 11-25.

34. Esposito M, Worthington HV, Coulthard P. Interventions for replacing missing teeth: treatment of perimplantitis. Cochrane Database Syst Rev. 2004; 4: CD004970.

35. Khammissa RA, Feller L, Meyerov R, Lemmer J. Periimplant mucositis and peri-implantitis: clinical and histopathological characteristics and treatment. SADJ. 2012; 67: 122, 124-6.

36. Loomer PM, Ellen RP, Tenenbaum HC. Characterization of inhibitory effects of suspected periodontopathogens on osteogenesis in vitro. Infect Immun. 1995; 63: 3287-96.
37. Kinane DF, Lappin DF. Immune processesin periodontal disease: a review. Ann Periodontol. 2002; 7: 62-71.

38. Sewerin I. Device for serial intraoral radiography with controlled projection angles. Tandlaegebladet. 1990; 94: 613-7.

39. Han TJ, Park KB. Surgical aspect of dental implants. In: Newman MG, Takei HH, Carranza FA (eds). Carranza's clinical periodontology. $9^{\text {th }}$ ed. Philadelphia: WB Saunders; 2002. p.898.

40. Barunawarty Y. Assessment of the increased calcification of jaw bone with CT-Scan after dental implant placement. Imaging Sci Dent. 2011; 41: 59-62. 